\title{
DEVELOPING TEAMS OF ENGINEERING DESIGN AND COMMUNICATION FACILITATOR-INSTRUCTORS
}

\author{
Jason A. Foster ${ }^{1}$, Robert Irish ${ }^{2}$, Patricia Kristine Sheridan ${ }^{3}$, Geoffrey S. Frost ${ }^{4}$, and Alan Chong ${ }^{2}$ \\ ${ }^{1}$ Division of Engineering Science, ${ }^{2}$ Engineering Communication Program, ${ }^{3}$ Institute for Leadership Education in Engineering, ${ }^{4}$ \\ Institute of Biomaterials and Biomedical Engineering, ${ }^{1,2,3,4}$ University of Toronto \\ jason.foster@utoronto.ca,r.irish@utoronto.ca, patricia.sheridan@utoronto.ca, geoff.frost@utoronto.ca, alan.chong@utoronto.ca
}

This presentation argues for the value of developing cross-disciplinary teaching teams for the design classroom as a way of enhancing the quality of instruction. Making such teams functional presents a unique challenge that requires developing a shared vision and values while simultaneously creating ongoing shared ownership of the course materials.

\section{THE CHALLENGE OF INTEGRATED INSTRUCTION}

Teaching engineering design has distinct, multifaceted challenges: students are as likely to generate problems as find solutions, while instructors struggle to support and assess diverse student work. In the cornerstone Praxis sequence of courses in the Engineering Science program at the University of Toronto, the teaching challenge is compounded by integrating engineering design with communication.

These open-ended, innovative, and multi-disciplinary courses create unique challenges for both the Design Teaching Assistants and Communication Instructors. Traditionally, instructors present their material independently, but ours co-develop material in front of students with a colleague. In integrating engineering design and communication instruction, instructors need to join in a creative space in which they develop a vision and sense of ownership for the entirety of the learning experience, not just their respective silos of expertise.

\section{DEVELOPING SHARED VISION AND OWNERSHIP}

In the Praxis Sequence, the teaching team focuses on developing a shared high-level vision of learning objectives for the course and students. The entire teaching team meets to develop shared strategies and approaches, not specific tactics for classroom activities. Once the vision is shared and the learning outcomes well understood, the team works collaboratively to develop specific activities. By that stage, the exact methods instructors use -- whether they follow, modify or outright reject recommended activities -- are not important as long as objectives are met. The collaborative approach of Praxis involves a significant investment in TAs and communication instructors but results in a cohesive, creative, and committed teaching team that co-creates the learning experience.

Trust among teaching team members creates shared ownership in the success of the course. Decisions are made collectively about activities, assessment, and assignment development by consulting at least part of the team. All instructors become deeply invested in the course. This translates into improved experience and more meaningful feedback for students, and strong collegiality among the diverse team.

Although the team is committed to making things work, not all compromise is easy. Real-time course implementation requires time to "fight out" ideas, challenge learning activities, or think through the student learning experience from different perspectives. In these meetings, every discussion is treated as a design problem in which conflict is encouraged and structured. The teaching team represent themselves and their students as stakeholders whose input is essential to develop the course. This process allows all team members' perspectives to be incorporated within the course philosophy.

\section{IMPLICATIONS FOR CROSS-DISCIPLINARY TEAM TEACHING}

In team-taught courses such as Praxis, ensuring integrity between the instructors and the course is essential, as it is apparent to the students. The teaching team must live out the values and content of the course in the manner in which they interact with their students, both in person and in print. In all assignments for students, we model what we teach in terms of applying the taught design process to the way in which we frame assignments. All assignments in Praxis are modelled as design reports, discussing stakeholder needs, defining requirements of the deliverable and discussing the motivation for the assignment in terms of the course learning objectives. By demonstrating the message we are trying to instil in students, design instructors can thereby encourage students to frame engineering design problems using effective engineering communication even as they frame communication as a design activity. 